\title{
Performance Monitoring of the Gas-Steam Combined Cycle Unit in Multi-Energy Power Grid
}

\author{
Xiang Wan, Niansu Hu, Pengfei Han and Shiqi Li \\ School of power and mechanical engineering, Wuhan University, Wuhan, Hubei 430072, China
}

\begin{abstract}
In power grid which contains a variety of power recourses (wind, solar and thermal power), the gas-steam combined cycle unit need to undertake the main peak load regulation task so that they have to work at the low load or variable load for a long time, and the operation method will have a significant economic impact on the unit. To solve this problem, the variation laws of the combined cycle economy are studied through the calculation, the extra value of gas consumption of the main parameters when they deviated from the target value based on the consumption difference analysis. The system we have developed provides guidance for the monitor of the properties of the unit, the dispatching of the power grid and the operation of the power plant.
\end{abstract}

Keywords-multi-energy power grid; combined cycle; performance monitoring; consumption difference

\section{INTRODUCTION}

In recent years, due to the good economical and environmental benefits, wind power generation and solar power generation are developed rapidly in China. But large-scale wind power plant and photovoltaic power plant are constructed in the area which is generally sparsely populated and far from the power grid load center, thus the power grid structure in the area is relatively weak. According to the intermittent and randomness of this volatility power connected to the power grid, especially it is difficult to predict accurately, control stably and adjust quickly, great challenges have been brought to the safe and stable operation of the power grid.

As gas-steam combined cycle ${ }^{[1-5]}$ power generating unit (combined cycle unit) has characteristics such as fast starting speed, fast load adjustment and stable operation, it has strong advantages in peak load regulation ${ }^{[6]}$. So an effective way is that the combined cycle power generation is added to the grid which wind and solar power grid generation have participated in, and then a multi-energy operation mode even including hydroelectric power is composed. The stability and reliability of such power grid is greatly enhanced by the multi-energy combined operation. A typical example is the multi-energy grid in Tarim, Qinghai, China.

In the multi-energy power grid, the combined cycle unit often operated at low load and the load changes frequently because of the need of the peak load regulation tasks. Then a great impact is caused on the economical efficiency of the unit, thus the cost of the power generation and the scheduling policy of the power grid are also influenced. Therefore, it is important to study the economical efficiency variation laws of the combined cycle unit operated at the peak load regulation conditions; particularly it is need to real-time monitor the influence of the efficiency of the overall unit caused by deviations of the main operating parameters.

\section{THE MODEL PARAMETERS OF COMBINED CYCLE UNIT}

The research objectives have been modeled, and the model parameters are as below.

\section{A. Gas Turbine}

The type of the gas turbine is PG9171E, the main parameters are: the rated load is123.529MW, compression ratio is 12.75 , the combustor exit temperature is $1120{ }^{\circ} \mathrm{C}$, the turbine exhaust temperature is $548.5{ }^{\circ} \mathrm{C}$, the turbine outlet pressure is $103.82 \mathrm{kPa}$ and the fuel is natural gas which low calorific value is $50040 \mathrm{~kJ} / \mathrm{kg}$.

\section{B. Heat Recovery Steam Generator (HRSG)}

The type of the gas turbine is double pressure no reheat no supplementary fuel, the rated inlet flue gas temperature is $548.4{ }^{\circ} \mathrm{C}$, the outlet temperature is $107.7^{\circ} \mathrm{C}$, the parameters of the high and low pressure superheated steam are $528{ }^{\circ} \mathrm{C} /$ 7.27MPa and $300{ }^{\circ} \mathrm{C} / 0.9 \mathrm{MPa}$ respectively and the efficiency is $83.33 \%$.

By analyzing the heat transfer process, the heat balance equation and mass balance equations for each part of the HRSG can be listed, then the high and low pressure main steam flow and exhaust gas temperature will be obtained by iterative solutions of these equations. According to the HRSG exhaust gas parameters, inlet feeding water parameters and the outlet steam parameters, the operating efficiency of the HRSG can be obtained.

\section{Steam Turbine}

The steam turbine is coaxial dual-cylinder dual-pressure extraction condensing steam turbine. The rated load is $125 \mathrm{MW}$, low-pressure cylinder exhaust steam pressure is $5.5 \mathrm{kPa}$ and the low-pressure cylinder exhaust steam outlet temperature is $34.5{ }^{\circ} \mathrm{C}$.

According to the calculated high and low pressure main steam flow, inlet and outlet steam parameters of the high and low pressure cylinder, output power, efficiency and other performance parameters can be calculated by the pros and cons balance of the turbine system.

\section{INFLUENCE OF THE LOAD ON THE ECONOMICAL EFFICIENCY OF THE COMBINED CYCLE UNIT}

The "Brayton Cycle" of the gas turbine and the "Rankine cycle" of the steam turbine are superimposed together to form the combined cycle system. Since both of the cycles affect each other at runtime, while the gas turbine operation is also 
influenced by environmental factors (such as ambient temperature and pressure), the variation laws of the economic performance of the combined cycle when the load changes are different from the laws in independent Brayton cycle and the Rankine cycle.

For gas turbine unit, the change of the ambient temperature ${ }^{[7]}$ will result in a corresponding change of the air density. When the ambient temperature increases, the air density decreases, and the specific volume increases. If the volume flow of the air inhaled by gas turbine compressor is constant, the mass flow of the air in the combustion chamber decreases, then the power capability after combustion in the gas turbine decreases. Besides, the temperature ratio and pressure ratio will decrease while the air temperature increases, thus the power consumption of the compressor will increases and the output work of the turbine decreases, which increases the heat consumption and reduces the output power of gas turbine and efficiency.

This feature of gas turbine is not only bound to be reflected in the combined cycle unit but also will influence the steam cycle unit. The increases of gas turbine efficiency will leads to the decreases of the gas turbine exhaust temperature, so that the efficiency and power of steam turbine cycle will decrease. Both of them determine the change of the efficiency of combined cycle as shown in Table 1.

TABLE I. THE EFFICIENCY OF THE COMBINED CYCLE UNEDR PEAK LOAD REGULATION.

\begin{tabular}{|c|c|c|c|c|c|c|c|c|c|}
\hline Name & $\begin{array}{c}\text { Ambient } \\
\text { Temperature }\end{array}$ & Unit & $100 \%$ & $93 \%$ & $85 \%$ & $77 \%$ & $69 \%$ & $60 \%$ & $50 \%$ \\
\hline \multirow{2}{*}{$\begin{array}{c}\text { Gas Turbine } \\
\text { Efficiency }\end{array}$} & 5 & $\%$ & 33.96 & 32.74 & 31.38 & 29.85 & 28.1 & 26.15 & 23.75 \\
\hline & 30 & $\%$ & 32.83 & 31.45 & 29.95 & 28.44 & 26.73 & 24.7 & 22.23 \\
\hline \multirow{2}{*}{$\begin{array}{l}\text { Steam Turbine } \\
\text { Cycle Efficiency }\end{array}$} & 5 & $\%$ & 25.62 & 26.28 & 26.95 & 27.51 & 27.89 & 27.92 & 27.90 \\
\hline & 30 & $\%$ & 27.70 & 28.45 & 28.90 & 29.06 & 29.10 & 29.10 & 29.07 \\
\hline \multirow{2}{*}{$\begin{array}{c}\text { Combined Cycle } \\
\text { Efficiency }\end{array}$} & 5 & $\%$ & 49.29 & 48.77 & 48.16 & 47.36 & 46.27 & 44.78 & 42.89 \\
\hline & 30 & $\%$ & 49.68 & 49.13 & 48.31 & 47.27 & 45.99 & 44.42 & 42.5 \\
\hline
\end{tabular}

Comprehensive calculations show that the efficiency of the combined cycle unit reduces when the load decreases. In peak load regulation process ${ }^{[8]}$, when the load decreases, inlet guide vane opening of the compressor will be reduced to maintain the temperature before the gas turbine at a constant value, so that the efficiency of the gas turbine will be maintained at a high level. However, inlet guide vane opening of the compressor cannot be reduced when the load ratio less than $85 \%$, otherwise, the last stage blade of the gas turbine will be overheating due to the compression ratio of the compressor drops too low. When the load decreases, due to the change of the gas turbine exhaust temperature, the efficiency of the turbine cycle increases in the first period and then maintains at a constant value. Thus the curve of the combined cycle efficiency is obtained as shown in Fig.1.

Figure 1 also reflects the influence of ambient temperature on the combined cycle efficiency. When the load ratio is higher than $85 \%$, the efficiency is higher when the ambient temperature is higher; the increase of the turbine efficiency plays the dominant role. For example, the difference between the two efficiencies is 0.39 percentage points at $100 \%$ load ratio. While when the load ratio is less than $85 \%$, the efficiency is higher when the ambient temperature is lower, the decrease of the gas turbine efficiency plays the dominant role.

\section{INFLUENCE OF MAIN OPERATING PARAMETERS ON THE ECONOMY IN COMBINED CYCLE UNIT}

Various operating parameters have a large deviation with the designed conditions at the peak load regulation load. They not only affect the economy of the unit on the whole unit, but also the influence weights of the various parameters on the economy are different, so it is need to monitor and analyze these parameters real-time in operation.

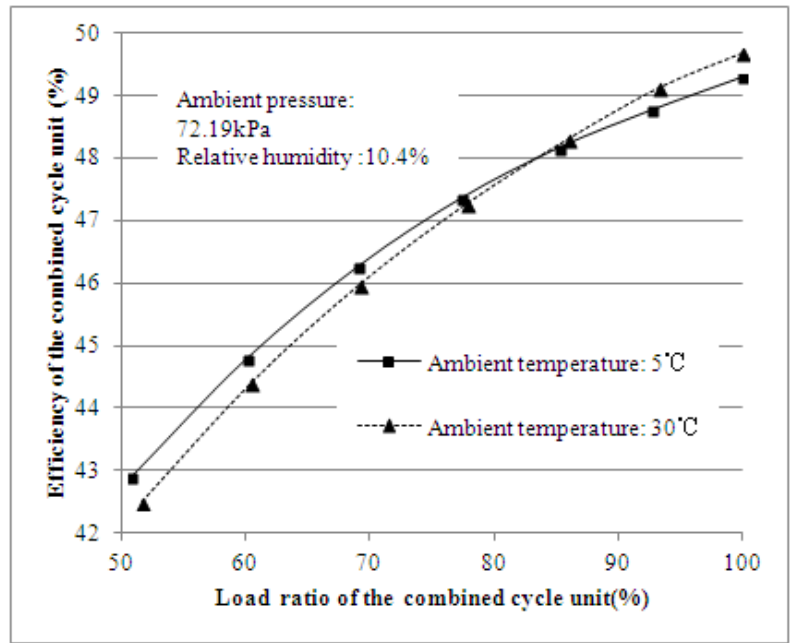

FIGURE I. THE RELATIONSHIP BETWEEN THE EFFICIENCY OF THE COMBINED CYCLE AND THE LOAD RATIO.

In this paper, the gas consumption rate is chosen as the study objective. Then consumption difference analysis is a method using the mathematical analysis methods to obtain the extra value of gas consumption by solving the exact differential of the gas consumption rate $y$ to various parameters $x_{i}$, based on the calculation model of the gas turbine, steam turbine and HRSG.

$$
\Delta y=\sum_{i=1}^{n} \frac{\partial f}{\partial x_{i}} \Delta x_{i}
$$

Taking the high pressure pinch point temperature difference of HRSG as an example, the high pressure pinch point temperature difference refers to the difference between the temperature of the flue gas side at high pressure evaporator 
inlet and the saturation temperature under the pressure of the high pressure drum. The increases of the high pressure pinch point temperature difference leads to the decreases of the evaporation of the high pressure drum, and the gas temperature of the HRSG outlet will increases with it, then the low pressure main steam flow will reduces. Thus the efficiency of the HRSG will decrease. The decreases of the low pressure main steam flow will influences the efficiency of the whole combined cycle unit, the output power of the steam turbine will decreases. Based on the above analysis, we know that when the high pressure pinch point temperature difference increases, the efficiency of the combined cycle reduces. Table 2 shows the consumption difference analysis calculation results of the high pressure pinch point temperature difference under different loads.

TABLE II. THE EXTRA GAS CONSUMPTION RATE OF HIGH PRESSURE PINCH POINT TEMPERATURE DIFFERENCE UNDER VARIABLE LOAD RATE $\left(\times 10^{-3} \mathrm{Nm}^{3} / \mathrm{kW} \cdot \mathrm{h}\right)$.

\begin{tabular}{|c|c|c|c|c|c|c|}
\hline $\begin{array}{l}\text { Temperature } \\
\text { Difference }\left({ }^{\circ} \mathrm{C}\right)\end{array}$ & $100 \%$ & $90 \%$ & $80 \%$ & $70 \%$ & $60 \%$ & $50 \%$ \\
\hline 20 & 0 & 0 & 0 & 0 & 0 & 0 \\
\hline 23 & 0.208 & 0.225 & 0.242 & 0.262 & 0.291 & 0.32 \\
\hline 26 & 0.417 & 0.45 & 0.485 & 0.525 & 0.583 & 0.641 \\
\hline 29 & 0.627 & 0.676 & 0.729 & 0.79 & 0.877 & 0.964 \\
\hline 32 & 0.837 & 0.904 & 0.975 & 1.055 & 1.171 & 1.289 \\
\hline 35 & 1.049 & 1.132 & 1.22 & 1.321 & 1.467 & 1.615 \\
\hline
\end{tabular}

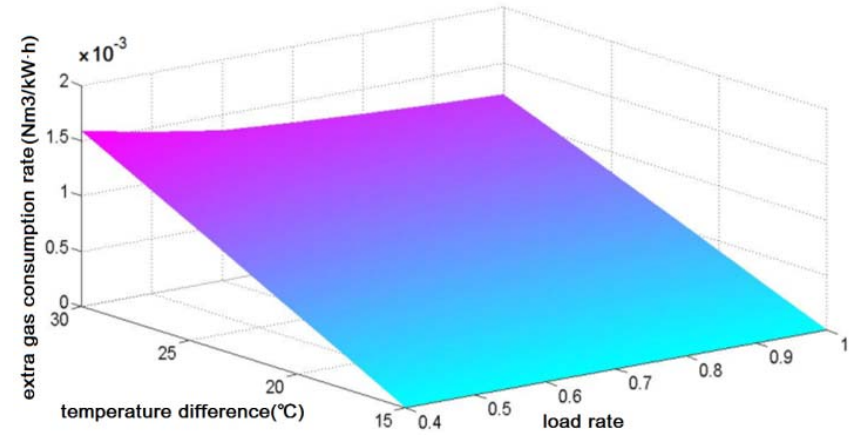

FIGURE II. CONSUMPTION DIFFERECE SURFACE OF HIGH PRESSUR PINCH POINT TEMPERATURE DIFFERENCE.

From the results of the Tab.2, the figure reflecting the extra value of gas consumption under different loads and different high pressure pinch point temperature differences can be drawn as shown in Figure 2.

As shown in Figure 2, when the load is a constant value, the extra value of gas consumption and the high pressure pinch point temperature difference show a linear relationship. And the growing speed of the combined cycle gas consumption is faster with the load decreases.

Similarly, the consumption difference curved surfaces of the other parameters can be obtained by calculating based on the theory of gas turbine, steam turbine and HRSG. These parameters include: gas turbine inlet pressure loss, gas turbine outlet pressure loss, gas turbine exhaust temperature, HRSG hot side temperature difference, HRSG deaerator pinch point temperature difference, HRSG exhaust gas temperature, steam turbine high pressure and low pressure main steam pressure and temperature, condenser temperature difference, condenser backpressure, circulating water temperature rise, supplementary water rate and so on.

\section{THE ONLINE MONITOR OF CONSUMPTION DIFFERENCE OF OPERATION PARAMETERS}

The target value of important working parameters should be ascertained to realize the online monitor of the combined cycle set. Particularly, the target value of the parameters are not constant, they change when the ambient temperature and load ratio are different. So this paper gets the target value with the method of Lagrange Interpolation on the basis of the target value of the parameters under different ambient temperature and load ratio. Then we can get the deviation of the parameters with the target values, which can be used to calculate the gas consumption rate on the basis of the two-dimension table with the same interpolation method. The result can help to assess the weight of influence that different parameters have on the gas consumption rate.

The bar and history trend line are used for online monitor $^{[9,10]}$, in which we can see clearly the target value, the operating value, the deviation and the gas consumption rate of different parameters, as shown in Figure 3. As the unit and ratio in the bars are unified, operators can easily observe the influence of different parameters on the operation of the combined cycle set, so that the operators can take measures to make sure that the set works under the best operating state.

\section{CONCLUSION}

The effect on economical efficiency when the combined cycle set operates under low load in the power grid with multi-energy operation was analyzed and the extra value of the gas consumption rate was calculated when the main operating parameters of the combined cycle set are not at the target values with the method of consumption difference analysis. It is convenient to observe the weight of influence that different operating parameters have on the economical efficiency of the combined cycle set. The online monitor system was developed on the basis of the research, which can offer help to the operators and administrators, as well as provide basis to the optimization of power grid dispatching. 


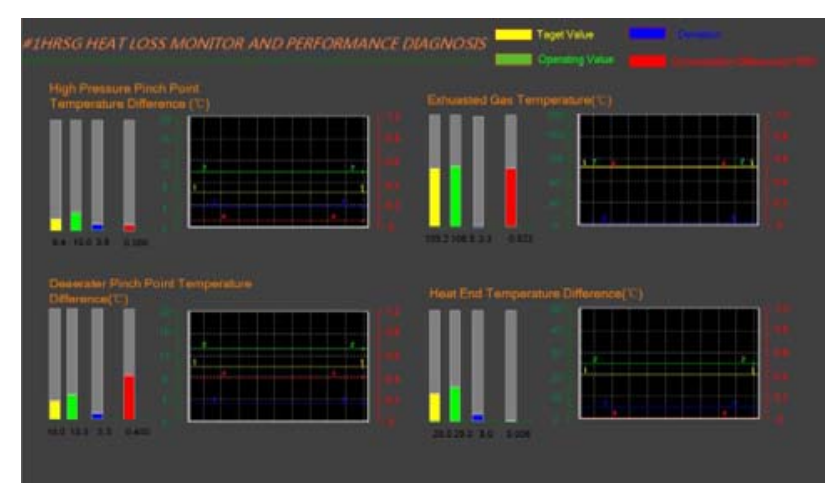

FIGURE III. ONELINE MONITOR OF THE CONSUMPTION DIFFERENCE.

\section{ACKNOWLEDGEMENT}

The supports from National Science and Technology Program (2013BAA02B01) are gratefully acknowledged.

\section{REFERENCE}

[1] J.H.Kim, T.S.Kim , J.L. Sohn. Comparative analysis of off-design performance characteristics of single and two-shaft industrial gas turbines [J]. Journal of Engineering for Gas Turbines and Power, 2003, 125(4) : 954-960.

[2] K.Mathioudakis. Analysis of the effects of water injection on the performance of a gas turbine [J]. Journal of Engineering for Gas Turbines and Power, 2002, 124(3) : 489-495.

[3] Frank J. Brooks. GE gas turbine performance characteristics[J]. GE Power Systems, GER-3567H, 2000, 10(00).

[4] A.Zwebek, P.Pilidis. Degradation Effects on Combined Cycle Power Plant Performance-Part I: Gas Turbine Cycle Component Degradation Effects. Journal of engineering for gas turbines and power, 2003, 125(3) : 651-657.

[5] Alessandro Franco, Alessandro Russo. Combined cycle plant efficiency increase based on the optimization of the heat recovery steam generator operating parameters. International Journal of Thermal Sciences, 2002, 41(9) : 843-859.

[6] J.Y .Shin, Y.J.Jeon, D.J. Maeng, J.S.Kim, S.T.Ro. Analysis of the dynamic characteristics of a combined-cycle power plant. Energy, 2002, 27(12) : 1085-1098.

[7] Felipe R.Ponce Arrieta, Electo E.Silva Lora. Influence of ambient temperature on combined-cycle power-plant performance. Applied Energy, 2005, 80(3) : 261-272.

[8] Chia-Chin Chuang, Deng-Chern Sue. Performance effects of combined cycle power plant with variable condenser pressure and loading. Energy, 2005, 30(10) : 1793-1801.

[9] Si-Moon Kim, Yong-Jin Joo. Implementation of on-line performance monitoring system at Seoincheon and Sinincheon combined cycle power plant. Energy, 2005, 30(13) : 2383-2401.

[10] S.Boonnasa , P. Namprakai , T .Muangnapoh. Performance improvement of the combined cycle power plant by intake air cooling using an absorption chiller. Energy, 2006, 31(12) : 2036-2046. 